\title{
Sonographic evaluation of Intima-Media thickness of carotid artery in healthy, hypertensive and diabetic Nepalese population
}

\author{
Shubhekshya Regmi*, Saroj Sharma, Hensan Khadka \\ Department of Radiology, NAMS, Bir Hospital, Kathmandu, Nepal
}

\begin{abstract}
Introduction: Hypertensionand Diabetes are two major risk factors for atherosclerotic disease. Carotid artery intima media thickness(cIMT) is considered a reliable surrogate measure for diagnosing subclinical atherosclerosis, its progression and regression. Paucity of available data regarding mean value of cIMT highlights the importance of defining the cut off value of cIMTin a specified population. Very limited studies have been done on sonographic evaluation of mean cIMT and carotid artery injury in hypertension and diabetes in Nepalese population. This study, therefore aims to determine mean cIMT in Nepalese population and to analyze effect of Hypertension and diabetes on cIMT. Methods: Cross-sectional hospital based study was conducted within the period of 18 months. B-mode ultrasound was used to measure cIMTin bilateral common carotid arteries. Comparison of mean cIMT was done amongst healthy, hypertensive and diabetes with hypertensive patients. Duration of disease was also considered. Data analysis was done with "R" analytical study. Results were expressed as mean \pm standard deviation. Results: Total1005 (508 female and 497 male) adult patients with age range of 30 to 85 years were assessed.Among these $329(32.74 \%)$ were healthy adults, 341(33.93\%) were hypertensive and 335(33.33\%) were diabetes with hypertensive patients. The mean cIMT in cases was more than controls $(\mathrm{P}<0.001)$ bilaterally with diabetes having an additive effect.There was also positive correlation of measured value with duration of disease and age of patients. Conclusion: The present study found that mean cIMT in cases was more than controls.There is an additional effect of Diabetes on cIMT in hypertensive patient. Age and duration of disease can accelerate atherosclerosis.
\end{abstract}

Keywords: Common Carotid artery, Intima media thickness, Nepalese population, ultrasound.

\section{Correspondence to:}

Dr. Shubhekshya Regmi

Senior Consultant Radiologist

Radiology Department,NAMS, Bir Hospital.

E-mail: drshubhekshya337@hotmail.com

Contact No:9851062067

Submitted: July 21, 2020

Accepted: October 30, 2020

To cite: Regmi S, Sharma S, Khadka H. Sonographic evaluation of Intima-Mediathickness of carotid artery in healthy, hypertensive and diabetic Nepalese population JGMC Nepal. 2020;13(2):116-21. DOI: 10.3126/jgmcn.v13i2.30937

\section{INTRODUCTION}

Chronic diseases with major health concern worldwide include hypertension, diabetes and chronic kidney diseases. Hypertension (HTN) and Diabetes Mellitus (DM) are the two most prevalent and major risk factors for atherosclerotic cardiovascular disease leading to death and disability. ${ }^{1-4}$ Researches have shown that atherosclerotic process occurs in carotid, cerebral and coronary arteries at the same time leading to various complications like ischemic heart disease, cerebrovascular accidents and peripheral vascular disease. ${ }^{4}$ Moreover, presence of DM has increased risk of coronary artery disease (CAD) and often causes silent ischemia. ${ }^{1,5}$ Thus early detection of atherosclerotic changes can prevent serious complications thereby decreasing morbidity and mortality. ${ }^{6}$

Carotid artery intima-media thickness (cIMT) measurement is considered a reliable surrogate measure of the initial phases of vascular atherosclerosis and is a strong predictor of its 
complications as it represents vessel wall alterations over time caused by different risk factors. ${ }^{1,4,7}$ Newer imaging techniques using ultrasound with inte-grated backscatter, Magnetic resonance imaging and multi-slice computerized tomography can directly visualize atherosclerotic changes in the arteries .Further, these techniques give additional information about plaque (lipid core, calcified, or ulcerated). ${ }^{8}$ Still B-Mode ultrasound is the modality of choice for cIMT measurement as it is non-invasive ,accurate, safe, cost effective and easily available tool. ${ }^{1,4,8}$

Multiple studies regarding the measurement of cIMT conducted in past have shown positive correlation between increased cIMT and cardiovascular risk factors and diseases, cerebrovascular accidents, however there is large variations of data regarding its mean diameter in the general population. . $^{1,7,9}$

Still limited researches have been done regarding the additional effect of DM on cIMT in hypertensive patient.,4 In context to Nepalese population, very limited studies have reported mean cIMT for cardiovascular risk assessment and to the best of our knowledge, the exact data regarding duration of disease and atherosclerotic changes is still not available in our country.

Therefore the main objective of this study is to measure the mean cIMTin Nepalese population and to assess the incidence of carotid injury in hypertensive patient, analyze the additional effect of DM and finally to find the correlation of cIMT with duration of disease.

\section{METHODS}

Cross-sectional hospital based study was conducted in the department of Radiodiagnosis of National Academy of Medical Sciences (NAMS), Bir hospital, Kathmandu over a period of 18 months from August 2018 till February 2019. We included both male and female patients between the ages of 30 and 85 years attending Radiology department for ultrasonography after obtaining informed consent.Ethical approval was obtained from IRB of the hospital. Patients were categorized to healthy control group, hypertensive group and hypertension with diabetes group. Duration of the diseases was considered in hypertensive group and hypertension with diabetes group.These groups were further categorized with disease duration less than 5 years, 5-10 years and more than 10 years. Participants with diabetic complications (Retinopathy, Neuropathy and Nephropathy), Renal disease, Secondary HTN,Cardiac or Cerebral disease, Fatty liver were excluded from the study. Hitachi, Aloka Ultrasound machine of radiology department of Bir hospital with high frequency linear probe (5-12 MHz) was used to measure and calculate the intima media thickness of common carotid artery (CCA).

The measurements were carried out by a single observer with the subject lying down, neck extended and head slightly turned in the direction opposite to the carotid artery being examined. Measurement of cIMT were done bilaterally at one centimeter below (proximal) the bifurcation of common carotid artery. ${ }^{10}$ The arteries were examined in the anterolateral, postero-lateral, and medio-lateral directions. Double-line density on an ultrasound image is identified allowing the definition of intima-media and media-adventitia interfaces.The distance between the intimal-luminal (LI) and the medial-adventitial (MA) is taken. Inter-faces is taken in a region without plaque as the cIMT measure as shown in Figure 1. Mean values of right and left CCA were calculated and expressed in millimeter. Data were entered in an word Excel and statistical analysis was performed with "R" analytical study and independent Z test was done to correlate between increased cIMTamong three groups and duration of the disease. Results were expressed as mean \pm standard deviation for mean Carotid IMT bilaterally.

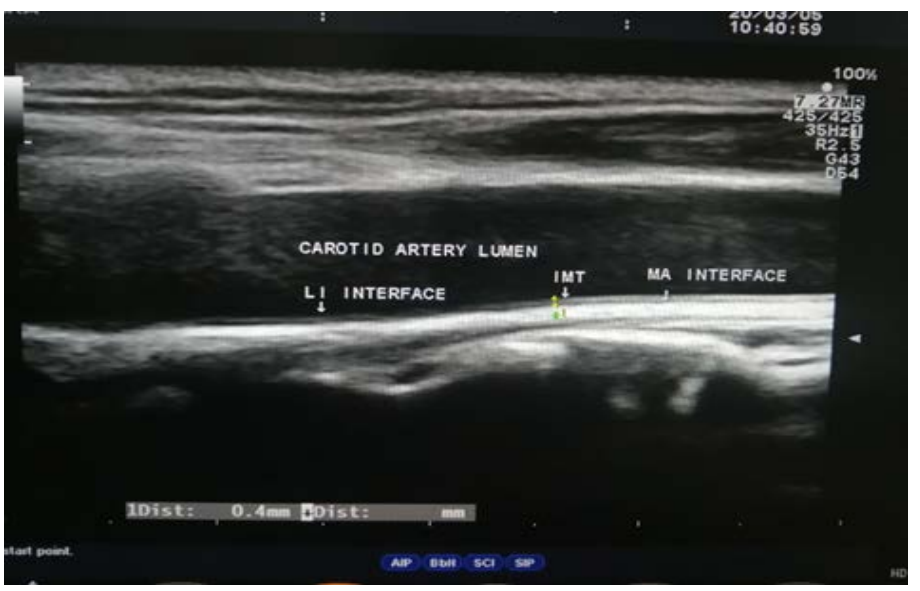

Figure 1: Intima-media complex in the CCA

\section{RESULTS}

Total 1005 adult patients who met the inclusion criteria were included in our study. 508 were female and 497 were male. Among them Normal healthy group were 329(32.74\%), Hypertensive group were 341(33.93\%), and Hypertensive along with Diabetic group were 335(33.33\%).Table 1 shows number of cases according to sex in three different groups of study.

Table 1: No of cases according to sex in various study groups

\begin{tabular}{|c|c|c|c|}
\hline \multirow{2}{*}{ Sex } & \multicolumn{3}{|c|}{ Group } \\
\hline & Normal & Hypertensive & Hypertensive + Diabetic \\
\hline Male & 170 & 152 & 175 \\
\hline Female & 159 & 189 & 160 \\
\hline
\end{tabular}


The mean cIMT in control group was $0.592 \pm 0.139 \mathrm{~mm}$ with range of $0.4-1.2 \mathrm{~mm}$ on right side and $0.594 \pm 0.151 \mathrm{~mm}$ ranging from $0.3-1.2 \mathrm{~mm}$ on left side.

In-patients with HTN, the mean cIMT of Right CCA was $0.856 \pm 0.157 \mathrm{~mm}$ with range of 0.5 to $1.4 \mathrm{~mm}$ and of Left CCA is $0.871 \pm 0.163 \mathrm{~mm}$ ranging from $0.5-1.3 \mathrm{~mm}$.

Similarly, in patients having both HTN and DM, the mean cIMT on right side was $1.0 \pm 0.15 \mathrm{~mm}$ with a range of $0.7 \mathrm{~mm}$ $1.3 \mathrm{~mm}$ and $1.02 \pm 0.148 \mathrm{~mm}$, ranging from $0.7-1.4 \mathrm{~mm}$ on left side.Table 2 shows variation of Mean IMT of CCA in threestudy groups.

Table 2: Mean intima media thickness (IMT) of CCA in three study groups

\begin{tabular}{ccccccccc}
\hline & \multicolumn{3}{c}{ Right CCA IMT } & \multicolumn{4}{c}{ Left CCA IMT } \\
Group & $\begin{array}{c}\text { Mean } \\
(\mathrm{mm})\end{array}$ & SD & $\begin{array}{c}\text { Mini- } \\
\text { mum } \\
\text { value } \\
(\mathrm{mm})\end{array}$ & $\begin{array}{c}\text { Maxi- } \\
\text { mum } \\
\text { value } \\
(\mathrm{mm})\end{array}$ & $\begin{array}{c}\text { Mean } \\
(\mathrm{mm})\end{array}$ & SD & $\begin{array}{c}\text { Mini- } \\
\text { mum } \\
\text { value } \\
(\mathbf{m m})\end{array}$ & $\begin{array}{c}\text { Maxi- } \\
\text { mum } \\
\text { value } \\
(\mathbf{m m})\end{array}$ \\
Normal & 0.592 & 0.139 & 0.4 & 1.2 & 0.594 & 0.151 & 0.3 & 1.2 \\
HTN & 0.856 & 0.157 & 0.5 & 1.4 & 0.871 & 0.163 & 0.5 & 1.3 \\
HTN+DM & 1.0 & 0.15 & 0.7 & 1.3 & 1.02 & 0.148 & 0.7 & 1.4 \\
\hline
\end{tabular}

Similarly box plot in Figure 2 shows the distribution of right and left cIMT in three groups which shows in comparison to normal healthy individual, there is increase in cIMT in hypertensive patient independently and there is an additive effect of diabetes on cIMT in patient with hypertension.

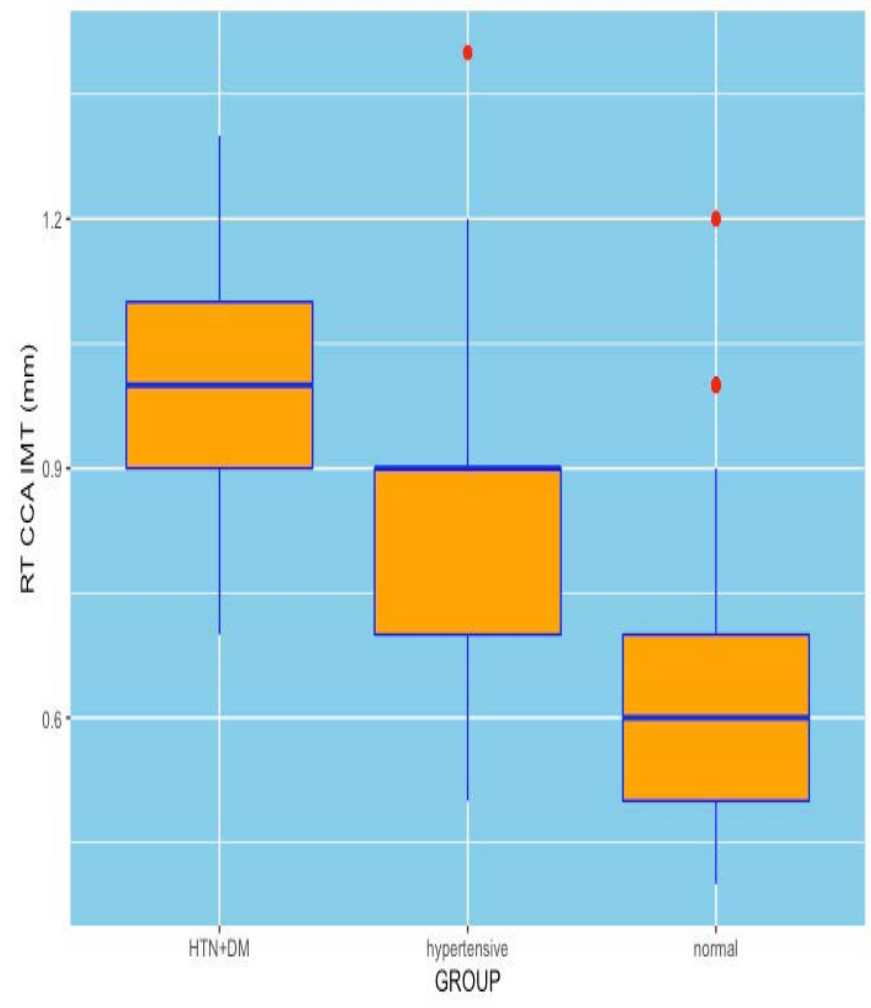

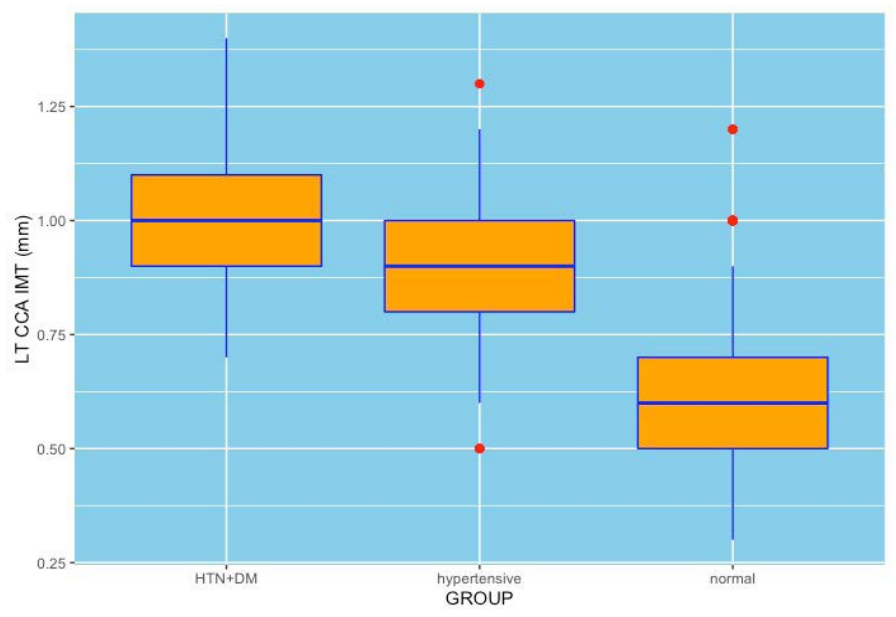

\section{Figure 2: Box plot showing effect of HTN and DM on cIMT}

The result also shows mean cIMT was directly affected by the duration of the disease.There is significant increase in cIMT with duration of the disease. Table 4 shows the effect of duration of HTN and HTN with DM on CCA IMT.

Table 4: Mean CCA IMT in correlation with duration of the disease

\begin{tabular}{ccccc}
\hline $\begin{array}{c}\text { Dura- } \\
\text { tion of } \\
\text { Disease } \\
\text { (years) }\end{array}$ & $\begin{array}{c}\text { Right CCA } \\
\text { Mean } \pm \mathbf{s d}(\mathbf{m m})\end{array}$ & $\begin{array}{c}\text { HTN+DM } \\
\text { Mean } \pm \mathbf{s d}(\mathbf{m m})\end{array}$ & $\begin{array}{c}\text { HTN } \\
\text { Mean } \pm \mathbf{s d ~}(\mathbf{m m})\end{array}$ & $\begin{array}{c}\text { HTN+DM } \\
\text { Mean } \pm \mathbf{s d}(\mathbf{m m})\end{array}$ \\
$<5$ & $0.747 \pm 0.131$ & $0.81 \pm 0.09$ & $0.748 \pm 0.146$ & $0.852 \pm 0.09$ \\
$5-10$ & $0.875 \pm 0.139$ & $0.959 \pm 0.093$ & $0.896 \pm 0.123$ & $0.996 \pm 0.108$ \\
$>10$ & $0.946 \pm 0.131$ & $1.12 \pm 0.09$ & $0.968 \pm 0.136$ & $1.13 \pm 0.09$ \\
\hline
\end{tabular}

In patients diagnosed as hypertensive for $<5$ years, cIMT was $0.747 \pm 0.131 \mathrm{~mm}$ on right side and $0.748 \pm 0.146$ on left sided, with duration 5 -10years is $0.875 \pm 0.139 \mathrm{~mm}$ on right side and $0.896 \pm 0.123 \mathrm{~mm}$ on left side and with duration $>10$ years $0.946 \pm 0.131 \mathrm{~mm}$ on right side and $0.968 \pm 0.136$ on left side. Similarly in patients with both hypertension and diabetes for <5years,Right cIMT was $0.81 \pm 0.09 \mathrm{~mm}$ and Left cIMTwas $0.852 \pm 0.09 \mathrm{~mm}$, with duration 5-10years was $0.959 \pm 0.093 \mathrm{~mm}$ on right side and $0.996 \pm 0.108 \mathrm{~mm}$ on left side and with duration $>10$ years was $1.12 \pm 0.09 \mathrm{~mm}$ on right side and $1.13 \pm 0.09$ on left side. The data is statistically significant $(\mathrm{P}=<0.001)$.

The value of right cIMT in female was $0.80 \pm 0.22 \mathrm{~mm}$ (mean $\pm S d$ ) and in males, $0.82 \pm 0.22 \mathrm{~mm}(\mathrm{p}$-value $=0.22$ ). The value of left cIMT in females was $0.81 \pm 0.23 \mathrm{~mm}$ and males, $0.84 \pm 0.22 \mathrm{~mm}$ ( $p$-value $=0.13$ ).No significant difference was observed between males and females andin right and left cIMT.

There was significant correlation of mean cIMTwithage. We performed Simple regression of cIMTon age. Age was significant to predict cIMT ( $\mathrm{p}$-value $=<0.001$ ). It was found 
that one-year increase in age increasescIMT by $0.01 \mathrm{~mm}$.

\section{DISCUSSION}

Increasing cIMT is an independent risk factor and a measurable one in the diagnosis of subclinical atherosclerosis. ${ }^{3,6,7,11}$ The main aim of our study was to assess the intima media thickness of CCA in healthy Nepalese population, measure effect of HTN alone and DM with HTN on cIMT and finally to analyze relation of carotid injury with duration of the disease.

In our study, cIMT on right side ranged from $0.4-1.2 \mathrm{~mm}$ with mean of $0.592 \pm 0.139 \mathrm{~mm}$ and $0.594 \pm 0.151 \mathrm{~mm}$ with the range was $0.3-1.2 \mathrm{~mm}$ on left side which is similar to the study done by Mirza et al, ${ }^{1}$ Stein et $\mathrm{al}^{12}$ and Grobbee et al. ${ }^{13}$ Value of mean cIMTin studies done by Baroncini et al, ${ }^{2} \mathrm{Go}^{\prime} \mathrm{mez}-$ Marcos et $a l,{ }^{9}$ Lee et $\mathrm{al}^{14}{ }^{14}$ Lundbyet. $\mathrm{al}^{15}$ and Djaberi et $\mathrm{al}^{5}$ in healthy individual were $0.42 \pm 0.05 \mathrm{~mm}, 0.686 \mathrm{~mm}, 0.73 \mathrm{~mm}$, $0.679 \pm 0.105 \mathrm{~mm}$ and $0.58 \pm 0.08 \mathrm{~mm}$ respectively. Study done by Sapkota et $\mathrm{al}^{16}$ showed mean cIMT on right side was 1.1468 mm (SD 0.375), whereas mean cIMT on left side was 1.137 $\mathrm{mm}$ (SD 0.35). Similarly Touboulet $\mathrm{al}^{17}$ shows meancIMT $0.773 \pm 0.142 \mathrm{~mm}$ and $0.726 \pm 0.149 \mathrm{~mm}$, Fracanzaniet $\mathrm{al}^{18}$ AL-Auqbi et $\mathrm{al}^{4}$ and Mahmoud et $\mathrm{al}^{10}$ showcIMT range of 0.5 to $0.8 \mathrm{~mm}, 0.715 \mathrm{~mm}(0.715-0.714 \mathrm{~mm})$ and $0.4-0.7 \mathrm{~mm}$ respectively in controls. Similarly Oli et $\mathrm{al}^{19}$ also found mean cIMT on right $0.73 \mathrm{~mm}$ and on left side $0.77 \mathrm{~mm}$. Our study is in tune with these studies. Howeverwide variations in the value of cIMT highlights the importance of defining the cut off value of mean cIMT in Nepalese population.

Despite the reference value of mean cIMT, various studies done in past found that cIMT was significantly higher in HTN not accounting for any treatment than that of the the healthy group. 1,3,9,14,17,19-22 The results of these studies are similar to our study. Also, the mean cIMT in study done by Mandal et $\mathrm{al}^{22}$ for hypertensive patient is within the range of our result. Lianget $\mathrm{al}^{23}$ also found that mean cIMT was increased in both smoking andHypertensive patient with increased the IMT/ Lumen ratio in HTN while smoking had no effect on this ratio proving that HTN has more additive effect on cIMT than other risk factors like smoking.

The variation in mean cIMT may also be attributed to differences in duration of the diseases. Various studies shows an annual increment in the thickness of cIMT in HTN and DM., 24-26 In our study, mean cIMT has significantly increased with the duration of the diseases and mean cIMT was highest in patient with both HTN and DM with disease duration>10years . Duration of disease thus increases the risk of carotid injury. Naseh et $\mathrm{al}^{3}$ contradict our findings. It was found that there was no difference between the duration of HTN and mean cIMT.This may be due to differences in sample size, study groups with history of hypertension for at least five years, techniques and equipments used for the study.

In our study patients having both hypertension and diabetes had the highest mean cIMT. Other study also mentions that HTN and DM has the greatest effect on mean cIMTthereby increasing risk of atherosclerosis. ${ }^{1,27}$ Considering duration of the disease also, diabetes has additive effect on cIMT which is similar to other studies. ${ }^{9,20}$ Study shows that use of hypoglycaemic drugs along with change in lifestyle may help in decreasing intimal thickness and preventing atherosclerotic related complications. ${ }^{1,28}$ Early detection of subclinical atherosclerosis may thus revert the process of atherosclerosis there by decreasing cardiovascular and cerebrovascular complications .

Considering right and left carotid arteries, mean cIMT was greater in cases in comparison to controls and no significant differences were found between right and left CCA. ${ }^{1,3,29}$ This also supports our study where there is no difference in mean cIMT of right and left CCA.

Regarding the sex of the patient, no significant difference was observed in measurement of cIMT between male and female which is in tune with study done by Naseh Get al. ${ }^{3}$ The correlation between age and mean cIMT was also found in our study which is similar to study done by Naseh et $\mathrm{al}^{3}$ and Su et al. ${ }^{30}$

We measured and compared mean cIMT among healthy, hypertensive and HTN with DM groups, which showed significant differences between control and hypertensive groups with DM having an additive effect. Result also showed significant correlation between increased cIMT and duration of the disease. Our study is thus comparable with previous studies. This implies that using similar equipment, methods and if done by a qualified radiologist, the measurement of mean cIMT can be reliable and is reproducible.

There are certain limitations in our study .We did not take the parameters like height, weight, BMI. We could not avoid the observer and technical errors.Some of the study shows that only IMT of internal carotid had a significant relationship with arterial risk factors such as age, sex, dyslipidemia HTN, diabetes, and smoking. ${ }^{3}$ Also Sapkota et $\mathrm{al}^{16}$ shows patient with multiple risk factors had high cIMT of $1.2628 \mathrm{~mm}(\mathrm{SD}$ 0.404).Further research should thus focus to determine the effect of these risk factors on CCA and its branches .Other limitation of the present study was that medical treatment administered to hypertension and diabetes was not considered. Lastly, the study was carried out only in patients who visited our hospital and may not be representative of the population. 


\section{CONCLUSION}

The mean cIMT in Nepalese population, incidence of carotid injury in HTN with DM having additional effect on carotid artery and correlation of carotid artery injury with duration of the disease and age of the patient has been established in our study. The results are comparable with previous studies, so it can be used as a baseline for future population based studies and clinical decision-making to prevent complications related to vascular atherosclerosis. Moreover the variations of cIMT with weight, height, blood lipid and smoking if considered in the study will definitely increases the sensitivity and specificity of ultrasonography for early detection and prevention of various vascular complications .

Conflict of interest: None declared

\section{Acknowledgements}

We would like to thankall the doctors of Department of Cardiology and Endocrinology of NAMS Bir hospital for referring the individuals for this study. In addition, we would like to thank Mr. Siddhartha Dhungana for his help in the statistical analysis.

\section{REFERENCES}

1. Mirza W, Bari V, Kazim M, Fatima K, Sajjad Z, Jiwani $A$, et al. Carotid intima media thickness evaluation by ultrasound comparison amongst healthy, diabetic and hypertensive Pakistani patients. J Pak Med Assoc. 2016;66(11):1396.

2. Baroncini LAV, Sylvestre L de C, Baroncini CV, Pecoits Filho R. Assessment of carotid intima-media thickness as an early marker of vascular damage in hypertensive children. Arq Bras Cardiol. 2017;108(5):452-7. DOI: 10.5935/abc.20170043

3. Naseh G, Fard MM, Kazemi T, Mirgholami A, Hashemi N, Saburi A. Comparison of carotid intima-media thickness in hypertensive patients and control group. J Cardiovasc Echography. 2016;26(2):48.DOI: 10.4103/22114122.183749

4. AL-Auqbi TF, Al-Sabbagh AA, Al-Karawi IN, MAJ B. Effect of hypertension on the carotid artery intima media thickness (IMT) in patients with type 2 diabetes mellitusacross sectional study. Int J Diabetes Res. 2014;3:66-70.

5. Djaberi R, Schuijf JD, de Koning EJ, Rabelink TJ, Smit JW, Kroft LJ, et al. Usefulness of carotid intimamedia thickness in patients with diabetes mellitus as a predictor of coronary artery disease. Am J Cardiol. 2009;104(8):1041-6. DOI: $10.1016 / \mathrm{j}$. amjcard.2009.06.004
6. Limbu YR, Rajbhandari R, Sharma R, Singh S, Limbu D, Adhikari CM, et al. Carotid intima-media thickness (CIMT) and carotid plaques in young Nepalese patients with angiographically documented coronary artery disease. Cardiovasc Diagn Ther. 2015;5(1):1.

7. Talelli P, Terzis G, Katsoulas G, Chrisanthopoulou A, Ellul J. Recurrent stroke: the role of common carotid artery intima-media thickness. J Clin Neurosci. 2007;14(11):1067-72.DOI: 10.1016/j.jocn.2006.06.019

8. Greenland P, LaBree L, Azen SP, Doherty TM, Detrano RC. Coronary artery calcium score combined with Framingham score for risk prediction in asymptomatic individuals. Jama. 2004;291(2):210-5. DOI: 10.1001/ jama.291.2.210

9. Gómez-Marcos MA, Recio-Rodríguez JI, RodríguezSánchez E, Patino-Alonso MC, Magallón-Botaya R, Martínez-Vizcaino $\mathrm{V}$, et al. Carotid intima-media thickness in diabetics and hypertensive patients. Rev EspCardiolEngl Ed. 2011;64(7):622-5. DOI: 10.1016/j. recesp.2010.10.025

10. Mahmoud MZ. Sonography of common carotid arteries' intima: media thickness in the normal adult population in Sudan. North Am J Med Sci. 2013;5(2):88. DOI: 10.4103/1947-2714.107523

11. Ren L, Cai J, Liang J, Li W, Sun Z. Impact of cardiovascular risk factors on carotid intima-media thickness and degree of severity: a cross-sectional study. PLoS One. 2015;10(12):e0144182. DOI: 10.1371/journal. pone. 0144182

12. Stein JH, Korcarz CE, Hurst RT, Lonn E, Kendall CB, Mohler $E R$, et al. Use of carotid ultrasound to identify subclinical vascular disease and evaluate cardiovascular disease risk: a consensus statement from the American Society of Echocardiography Carotid Intima-Media Thickness Task Force endorsed by the Society for Vascular Medicine. J Am Soc Echocardiogr. 2008;21(2):93-111. DOI: $10.1016 /$ j.echo.2007.11.011

13. Grobbee DE, Bots ML. Carotid artery intima-media thickness as an indicator of generalized atherosclerosis. J Intern Med. 1994;236(5):567-73. DOI: 10.1111/j.13652796.1994.tb00847.x

14. Lee CD, Folsom AR, Pankow JS, Brancati FL. Cardiovascular events in diabetic and nondiabetic adults with or without history of myocardial infarction. Circulation. 2004;109(7):855-60. DOI: 10.1161/01. CIR.0000116389.61864.DE 
15. Lundby-Christensen L, Almdal TP, Carstensen B, Tarnow L, Wiinberg N. Carotid intima-media thickness in individuals with and without type 2 diabetes: a reproducibility study. Cardiovasc Diabetol. 2010;9(1):40. DOI: $10.1186 / 1475-2840-9-40$

16. Sapkota K, Dhakal B, Thapa J. Correlation of Carotid Artery Intima-Media Thickness in Patients with Ischemic Stroke and Its Risk Factors. In: Cerebrovascular Diseases. Karger Allschwilesterase 10, CH 4009 Basel, Switzerland; 2017.p.42.

17. Touboul P-J, Labreuche J, Vicaut E, Amarenco P. Carotid intima-media thickness, plaques, and Framingham risk score as independent determinants of stroke risk. Stroke. 2005;36(8):1741-5. DOI: 10.1161/01. STR.0000174490.23495.57

18. Fracanzani AL, Burdick L, Raselli S, Pedotti P, Grigore L, Santorelli G, et al. Carotid artery intima-media thickness in nonalcoholic fatty liver disease. Am J Med. 2008;121(1):72-8. DOI: 10.1016/j.amjmed.2007.08.041

19. Oli KK, Pradhan S, Agrawal JP. Ram K. Ghimire, MD. Nepal J Neurosci. 2005;2(2):117-21.

20. Sasaki R, Yamano S, Yamamoto Y, Minami S, Yamamoto J, Nakashima T, et al. Vascular remodeling of the carotid artery in patients with untreated essential hypertension increases with age. Hypertens Res. 2002;25(3):373-9. DOI: $10.1291 /$ hypres. 25.373

21. Chironi G, Gariepy J, Denarie N, Balice M, Megnien J-L, Levenson J, et al. Influence of hypertension on early carotid artery remodeling. ArteriosclerThrombVasc Biol. 2003;23(8):1460-4. DOI: 10.1161/01. ATV.0000083342.98342.22

22. Md DBChM, Md; DSPP, Md; DAB, Sarkar; ProfN. Impact of Prehypertension on Carotid Artery Intima Media Thickness. IOSR J Pharm IOSRPHR. 2014 Apr 18;04(04):08-10. DOI: 10.9790/3013-0404.08-10

23. Liang Y-L, Shiel LM, Teede H, Kotsopoulos D, McNeil J, Cameron JD, et al. Effects of blood pressure, smoking, and their interaction on carotid artery structure and function. Hypertension. 2001;37(1):6-11.DOI: 10.1161/01.HYP.37.1.6
24. Lorenz MW, von Kegler S, Steinmetz H, Markus HS, Sitzer M. Carotid intima-media thickening indicates a higher vascular risk across a wide age range: prospective data from the Carotid Atherosclerosis Progression Study (CAPS). Stroke. 2006;37(1):87-92. DOI: 10.1161/01. STR.0000196964.24024.ea

25. Jarauta E, Mateo-Gallego R, Bea A, Burillo E, Calmarza $P$, Civeira F. Carotid intima-media thickness in subjects with no cardiovascular risk factors. Rev EspCardiolEngl Ed. 2010;63(1):97-102. DOI: 10.1016/S03008932(10)70014-2

26. Puato M, Palatini P, Zanardo M, Dorigatti F, Tirrito $C$, Rattazzi $M$, et al. Increase in carotid intimamedia thickness in grade I hypertensive subjects: white-coat versus sustained hypertension. Hypertension. 2008;51(5):1300-5. DOI: 10.1161/ HYPERTENSIONAHA.107.106773

27. Meigs JB, Larson MG, D’Agostino RB, Levy D, Clouse ME, Nathan DM, et al. Coronary artery calcification in type 2 diabetes and insulin resistance: the Framingham Offspring Study. Diabetes Care. 2002;25(8):1313-9.DOI: 10.2337/diacare.25.8.1313

28. Langenfeld MR, Forst T, Hohberg C, Kann P, Lubben G, Konrad T, et al. Pioglitazone decreases carotid intima-media thickness independently of glycemic control in patients with type 2 diabetes mellitus: results from a controlled randomized study. Circulation. 2005;111(19):2525-31. DOI: 10.1161/01. CIR.0000165072.01672.21

29. Ayoola 00, Onuwaje MA, Akintomide AO. Sonographic assessment of the carotid intima-media thickness on B-mode ultrasonography in a Nigerian population. Niger Med J J Niger Med Assoc. 2015;56(5):357. DOI: 10.4103/0300-1652.170384

30. Su T-C, Chien K-L, Jeng J-S, Chen M-F, Hsu H-C, Torng P-L, et al. Age-and gender-associated determinants of carotid intima-media thickness: a community-based study. J AtherosclerThromb. 2012;19(9):872-80. DOI: $10.5551 /$ jat.10728 